\title{
Developmental level and concept-learning: A replication "2
}

STANLEY R. FRIEDMAN ${ }^{3}$

CHILD PSYCHIATRY RESEARCH CENTER

A developmental study of sequential-pattern identification had indicated that 3rd-graders performed more efficiently than 4 th-graders. The present study replicates that finding.

A number of studies (e.g., Friedman, 1965; Klugh, Colgan, \& Ryba, 1964; Torrance, 1961, 1962; Yamamoto, 1962) using various types of problems have found fourth graders to perform less efficiently than third graders. Friedman (1965) suggested that the fourth graders had reached a transitional developmental level where the inexpert use of a newly developing problem-solving technique reduced intellectual efficiency. The present study is a replication of an earlier one (Friedman, 1965).

\section{Subjects}

Two groups of nursery school students were used. The younger group consisted of eight males and nine females, had a mean age of 5-0 years, average deviation 1.8 months; the older group had nine males and eight females, with a mean age of 5-9 years, average deviation 2.8 months. The elementary school children were distributed as follows: first grade25 male, 33 female; second grade -22 male, 20 female; third grade-23 male, 26 female; fourth grade-24 male, 29 female; fifth grade-20 male, 14 female; sixth grade-21 male, 25 female. Only Ss in the proper age-grade placement (never having repeated a grade) were used in this study.

\section{Procedure}

The apparatus has been described elsewhere (Friedman, 1965); it consists of a display panel with five doors facing the S. Plastic tokens are placed behind the doors in various sequential orders, each token remaining behind the appropriate door until located and removed by $S$, at which time a token is placed behind the next door in the sequence. $S$ is given 50 trials (door openings) for each sequence and is instructed to find as many tokens as he can. Four sequential orders were used: $2,2, \ldots, 4,2,4,2, \ldots$; $1,3,5,1,3,5, \ldots ; 3,3,5,3,3,5, \ldots$ (the numbers refer to the doors, Door 1 being the door to the S's left). The scoring system used has been described earlier (Friedman, 1965); basically, it establishes a criterion level for each sequence.

Results

As in the earlier studies, there is a generally continuous increase with grade in the percentage of Ss successfully producing each sequence, except for the expected inversion (mean drop of 12.4 percentage points, with a range of 8.2-19.7) at the fourth grade (for each sequence). A class-by-class comparison showed that the academically superior third grade class surpassed the academically superior fourth grade class on all four sequences. No consistent sex differences were evident.

Research is now underway in an attempt to identify the specific variables associated with the inversion.

\section{References}

Friedman, S. R. Developmental level and concept learning: confirmation of an inverse relationship. Psychon. Sci., 1965, 2, 3-4.

Klugh, H. E., Colgan, Kay, \& Ryba, Judith A. Developmental level and speed of relational concept formation: a possible inverse relationship. Psychon. Sci., 1964, 1, 89-90.

Torrance, E. P. Factors affecting creative thinking in children: an interim research report. Merrill-Palmer Quart., 1961, 7, 171-180.

Torrance, E. P. Cultural discontinuities and the development of originality of thinking. Except. Child. 1962, 29, 2-13.

Yamamoto, K. Development of ability to ask questions under specific testing conditions. J. genet. Psychol., 1962, 101, 83-90.

\section{Notes}

1. The research reported herein was performed pursuant to a contract with the United States Department of Health, Education, and Welfare, Office of Education, under the provisions of the Cooperative Research Program.

2. The author expresses his appreciation to: Dr. Lovick C. Miller for his helpful assistance with this project; the Louisville Board of Education and Mrs. Chance's Community PreSchool for making available the Ss; Betty Clark, Shirley Dumesnil, Betty Brook McCord, Nancy McElwain, and Margery Strater for help in the running of Ss.

3. Authors address: Child Psychiatry Research Center, 608 South Jackson, Louisville, Kentucky. 